\title{
Sound the alarm
}

\author{
Five Days at Memorial: Life and Death \\ in a Storm-Ravaged Hospital \\ Sheri Fink \\ Crown Publishers; 2013
}

$\mathrm{I}$ n August 2005, Katrina, a monstrous category-three hurricane, slammed into the city of New Orleans, causing the dykes to overflow, the electricity to go off and chaos to ensue at the city's hospitals, including Memorial Medical Center. As water levels rose, the hospital's electrical generators, located in the lower levels of the building, were soon rendered useless. In her book, Five Days at Memorial, Dr. Sheri Fink, a Pulitzer Prize-winning physician-journalist, tells the harrowing tale of patients, staff, family members and pets who were marooned at the hospital. Over the next five days the staff struggled, mostly heroically, to look after their helpless charges as one system after another blinked out.

Fink began researching this book in 2007 and copublished an investigative report with The New York Times, in ProPublica. The book gives all (and perhaps more) of the details that a general medical reader might want and is documented with almost 500 footnotes, but the reader in a rush can get the general story from the aforementioned online report. For a more in-depth discussion, including profiles of the the people involved and analysis of the knotty ethical problems that arise in such an emergency, the full book is a tour de force and is a worthwhile read for the full spectrum of medical practitioners - from family doctors to hospital administrators.

Dilemmas relating to triage, euthanasia and who should make such decisions are not strictly medical issues, but issues that society as a whole must face. This book, by describing very extreme life-or-death scenarios in conditions of chaos, offers ample material for a broad range of readers.

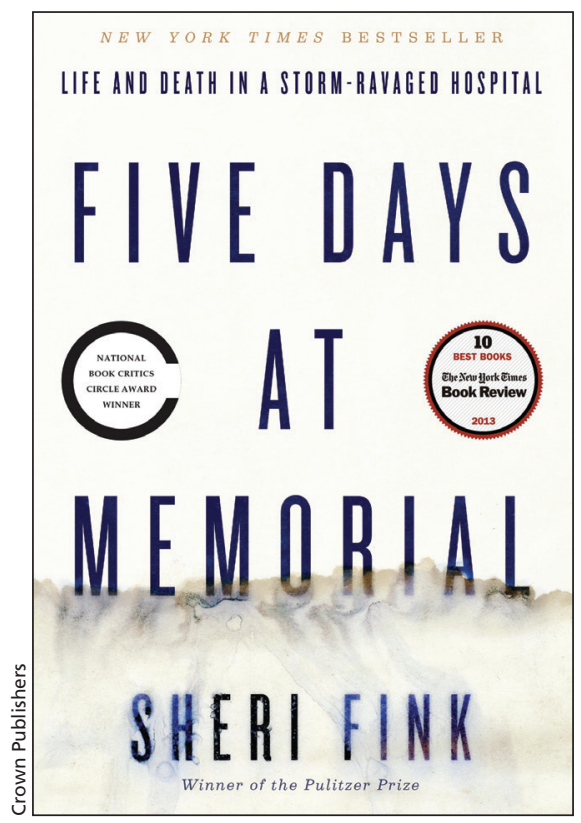

Although Fink discusses many of the main players in this real-life drama, her focus is on Dr. Anna Pou, a respected ear, nose and throat surgeon who euthanized (no other word really fits) several patients whom she feared might be left behind to die untended as the hospital reached the end of its evacuation phase. She was charged with administering heavy doses of morphine, midazolam, or both, to these patients, including some who were not considered terminal. This invites discussion about the "double effect" of palliative care, a term that refers to the delicate balance between palliating a patient's symptoms and the knowledge that palliation may well shorten the patient's life. The distinction lies in the order of these thoughts and in the overall intention to ease suffering or to euthanize.

After the hospital was fully evacuated, patients were indeed left behind to die. Questions were raised about whether Pou, and the two nurses who assisted her, were justified in their actions, given the extraordinary circumstances. In the end, Pou was exonerated by a State of Louisana grand jury. She has since become a stalwart advocate for new and realistic laws and regulations relating to medical and institutional behaviour during catastrophes. Still, even understanding her intentions and with all my sympathies for the situation in which Pou found herself, I still question whether what she did was right.

Much of the book describes the chaotic, uncoordinated and, in many cases, incompetent attempts by local, state and federal authorities to rescue marooned patients and staff. There are many bizarre scenes, such as the SWAT team that arrived by boat on day three, responding to a call that thugs had overrun the hospital and were trying to loot the pharmacy. Quickly finding this not to be the case, they left, not bothering to take anyone with them.

In such complex and emergent situations, it is hardly helpful to point a finger at one individual case or person. As such, Fink asks (rhetorically):

"Were deaths at hospitals and nursing homes regrettable results of an act of nature, a chaotic government response, and poorly constructed flood protection overlaid on a degraded environment? Or had lax oversight allowed individual or corporate greed to play a role? Did some hospital and nursing home leaders decide not to evacuate before the storm primarily to avoid the substantial costs of emptying and closing health facilities? Were emergency plans not followed, important pre-storm investments not made, and health workers not properly prepared?"

Of course, the answer is yes to all these questions, as Fink takes pains to explain in this important warning to all.

\section{A. Mark Clarfield MD}

Medical School for International Health and the Sidonie Hecht Professor of Geriatrics

Ben-Gurion University of the Negev

Beer-sheva, Israel

CMAJ 2015. DOI:10.1503/cmaj.140397 